\title{
The acceptance and applicability of a patient-reported experience measurement tool in oncological care: a descriptive feasibility study in northern Germany
}

Christiane Rudolph ${ }^{1 *}$ (D) Gitte Stentebjerg Petersen ${ }^{2}$, Ron Pritzkuleit ${ }^{1}$, Hans Storm ${ }^{2}$ and Alexander Katalinic ${ }^{1}$

\begin{abstract}
Background: Patient-reported outcome measures (PROMs) and patient-reported experience measures (PREMs) are tools for assessing outcomes of and experiences with health care from the patient's perspective. In Germany, PROMs are widely used in research for evaluating patient outcomes and quality of care. However, the application of PREMs is rather scant, especially in oncology. The study aimed to assess the feasibility of patient-centred quality evaluation in oncological care in Germany using the German adaptation of the Danish National Cancer Patient Questionnaire. This questionnaire is a PREM/PROM-tool addressing patients of all cancer sites and covering the entire cancer patient pathway.
\end{abstract}

Methods: The Danish National Cancer Patient Questionnaire was translated into German via forward-backward translation. Face-validity was tested among three cancer patients in a conventional pre-test. The German adaptation contains 99 questions. A pilot test was carried out among 245 newly diagnosed breast and colorectal cancer patients in the German federal state Schleswig-Holstein. Patients were recruited via clinics participating in the Oncological Care Registry (12 specialised units in seven hospitals) and contacted six to nine months after diagnosis. Response behaviour and response patterns were compared to the Danish study population $(n=1964)$.

Results: The willingness among clinicians to support patient recruitment as well as the response rate of patients to the questionnaire was high (65\%). Moreover, response behaviour and response patterns of German and Danish patients were consistent. Despite the generally good response behaviour of patients to the single items, the authors observed that questions assessing the diagnostic process did not fully capture German pathways. Only 19.3\% of the German patients stated that their diagnostic process was initiated by a visit to a general practitioner (GP) in contrast to $52 \%$ in Denmark. The assessment of patient experiences in the diagnostic phase heavily focuses on experiences in general practice, which does not seem appropriate in the German health care setting.

Conclusion: The translation was successful, and the feasibility of a future large-scale study within existing structures is given. However, some modifications of questions heavily related to the Danish health care system, especially referring to the diagnostic phase, are necessary.

Keywords: Breast cancer, Colorectal cancer, Patient-centered care, Patient preference, Patient satisfaction, Quality of health care, Pilot study

\footnotetext{
* Correspondence: christiane.rudolph@uksh.de

${ }^{1}$ Institute for Cancer Epidemiology, University of Lübeck, Ratzeburger Allee

160, 23562 Lübeck, Germany

Full list of author information is available at the end of the article
}

(c) The Author(s). 2019 Open Access This article is distributed under the terms of the Creative Commons Attribution 4.0 International License (http://creativecommons.org/licenses/by/4.0/), which permits unrestricted use, distribution, and reproduction in any medium, provided you give appropriate credit to the original author(s) and the source, provide a link to the Creative Commons license, and indicate if changes were made. The Creative Commons Public Domain Dedication waiver (http://creativecommons.org/publicdomain/zero/1.0/) applies to the data made available in this article, unless otherwise stated. 


\section{Background}

The patient's perceptive is of paramount importance for the assessment of health care quality and essential for providing patient-centred care. Patient evaluations are the only source of information about health care quality with regard to several aspects of care such as information provided, communication and interaction with medical staff or quality of life. Patient-reported measures have thus gained increasing importance in the evaluation of health care in addition to, for example, clinical quality indicators $[1,2]$. There are two categories of patientreported measures: Patient-reported outcome measures (PROMs) and patient-reported experience measures (PREMs). While PROMs measure health care outcomes (e.g. side effects or health-related quality of life), PREMs assess patient's needs and experiences whilst receiving care (e.g. involvement in care decision making or accessibility of services) [3].

In Germany, PROMs, especially quality of life measures, are widely and routinely used across various medical disciplines [4-8] including oncology [9-13]. The application of PREMs, however, is rather scant, especially in oncological care. Most studies focus on patient experiences in either outpatient $[14,15]$ or inpatient [16-20] care settings using generic instruments. Patient surveys designed specifically to assess cancer patients' experiences are scarce in Germany and limited to inpatient care of a specific cancer site [21] or to outpatient care [22]. Most instruments are limited to hospital care, which is not sufficient in cancer care. The diagnostic phase is often initiated in general practice or specialised outpatient care [23], and also rehabilitation is a significant part of the cancer trajectory $[24,25]$. In fact, a systematic review showed that cancer patients rate the diagnostic phase as the most important dimension of cancer care [26]. Thus these aspects have to be included in the evaluation of cancer care quality. To our knowledge, there is no publicly available PREM-tool in the German language that addresses cancer patients of all cancer sites and covers the entire cancer patient pathway from initial contact to a health care service provider until discharge from hospital. Such a tool would allow identification of care aspects along the entire cancer trajectory, where patient preferences and needs are inadequately addressed. As patient-centred health care and positive patient experiences are associated with better adherence to treatment and thus with better outcomes, the utilisation of such a survey instrument and the reporting of patient experience data is an essential step towards improving cancer care [27, 28].

Since 2009, The Danish Cancer Society have developed and adjusted/improved tools for assessing patientreported experiences and outcomes in oncological care throughout the entire patient pathway $[29,30]$. In 2017 , a survey based on the Danish National Cancer Patient Questionnaire was conducted among newly diagnosed cancer patients. The aim was to explore cancer patients' needs and experiences regarding diagnostic care and treatment in Denmark [31]. The same year the Danish questionnaire was translated into German. A pilot study using the German adaptation was carried out among newly diagnosed patients with breast cancer and colorectal cancer in the northernmost German federal state Schleswig-Holstein. The aim of this study was i) to assess the feasibility of patient-centred quality evaluation in oncological care in Germany within existing structures ii) to explore the acceptance and applicability of the German adaptation of the Danish National Cancer Patient Questionnaire in the German health care setting and iii) to collect the initial information on patientreported experiences in Schleswig-Holstein in comparison to Denmark.

\section{Methods}

In the German federal state Schleswig-Holstein, a feasibility study was conducted using the German adaptation of the Danish National Cancer Patient Questionnaire (2017-version).

\section{The Danish cancer patient questionnaire}

The Danish National Cancer Patient Questionnaire (2017-version) is a self-administered data collection tool containing 129 questions of which several are multi-item scales. The questionnaire covers the entire cancer patient pathway from diagnosis over treatment to discharge from hospital. The tool was developed by the Danish Cancer Society in 2010 [29]. The first version of the tool was extensively revised in 2016-2017 in a multi-stage process [31], including:

- Literature search in PubMed and Google was carried out in order to identify relevant topics for patientcentred health care evaluation among cancer patients in addition to relevant topics included in previous versions of the tool.

- An online survey (533 cancer patients responded), focus groups and individual interviews were conducted to identify important issues or aspects encountered in cancer care to strengthen the patients' perspective in the questionnaire development.

- Patient representatives, clinicians and researchers summarised the identified topics from literature search, patient survey and interviews and critically evaluated the items to be included in the questionnaire.

- A pilot test was conducted among 559 cancer patients to validate 18 new PREMs included in the 
2017-version. Furthermore, 22 cognitive interviews were conducted among cancer patients in order to validate the whole questionnaire.

\section{Translation and adaptation of the Danish tool}

Two-thirds of the Danish questionnaire consist of PREMs and one-third includes a range of validated PROM-scales such as the EORTC-QLQ-C30 Quality of Life assessment tool and sub-scales of the Work Ability Index (WAI) and Health Literacy Questionnaire (HLQ), for which validated German translations are already available [32-34]. We identified questions that were specifically targeting the Danish health care system or Danish research collaborations and thus were not applicable to Germany. Additionally, nineteen questions (all PREMs) were removed from the questionnaire in order to slightly shorten the extensive tool. For the remaining questions, that were to be included in the German version and for which no German translation was already available, a forward-backward translation was conducted in order to obtain a translation as valid as possible. The procedure of a forward-backward translation involved a translation from Danish to German by a project member (CR) and a back-translation from German to Danish by a third independent person (professional translator). Thereafter an expert panel including researchers and a communication consultant working in the project compared the two Danish versions and derived at a more precise German translation of the questionnaire. Some questions and their respective response categories had to be adapted to the German health care and social security system. Subsequently, a conventional pre-test among three cancer patients was conducted, which did not lead to major changes in the translation and established face validity. The German version contains 99 questions of which several are multi-item scales resulting in a total of 157 items on 20 pages. It takes approximately an hour to fill out the questionnaire (Additional file 1: Figure S1).

\section{Feasibility outcomes of the pilot study in Schleswig- Holstein, Germany}

Feasibility outcomes were defined and operationalised in accordance with the study objectives as follows: i) The feasibility of a patient-centred quality assessment in oncological care within the existing structures of the health care system was assessed on the basis of the willingness of the contacted hospital departments to support the study by recruiting patients. ii) Acceptance and applicability of the German adaptation of the Danish National Cancer Patient Questionnaire in the German health care setting were assessed by response rate, proportion of missing values and comparison of response patterns across countries. iii) Additionally, initial descriptive comparisons of patient-reported experiences in SchleswigHolstein and in Denmark elicited information on the consistency of responses.

\section{Data collection in Germany and Denmark}

The German adaptation of the questionnaire was tested among colorectal and breast cancer patients in Schleswig-Holstein, Germany. The patients were 30 to 99 years old and newly diagnosed between January and March 2017. Patients with carcinomas in situ and male breast cancer patients were not included in the study. The patients were recruited via clinics in the Oncological Care Registry (Onkologisches Versorgungsregister) in Schleswig-Holstein. We invited eight hospitals with thirteen specialised units to participate in the pilot study. Within existing patient data exchange routines in the oncological care registry, patient contact information as well as information on sex, age, date of diagnosis and cancer site (diagnosis according to the ICD-10) were delivered by the hospitals for all breast and colorectal cancer patients treated at the respective hospital fulfilling the above mentioned in- and exclusion criteria. The questionnaire was sent out by the cancer registry to 245 patients six to nine months after diagnosis. In contrast to the Danish survey, patients could fill out and send back a paperbased version of the questionnaire only. After three weeks, patients who had not responded by then were invited once again to participate. Ethical approval for the German pilot study was obtained from the Ethical Committee at the University of Lübeck.

Data collected in the German pilot study was compared to results of the Danish nationwide population-based survey, which was conducted among cancer patients aged 30 to 99 years. Patients were identified through the National Patient Registry [35] and included patients registered with a cancer diagnosis for the first time between July and December 2016. The Danish National Cancer Patient Questionnaire was distributed four to seven months after diagnosis. Patients could either fill out and send back the paper-andpencil version or use the web-based survey. For comparability with the German survey, we restricted the sample from Denmark to female breast cancer cases and colorectal cancer cases of both sexes. In total, 3399 Danish breast and colorectal cancer patients were eligible and received a questionnaire. The Danish study was approved by the Danish Data Protection Agency. Under Danish law, questionnaire studies are not subject to review by the Ethics Committee System.

Within the scope of this article, we focus on patientreported experience measures and exclude further exploration of validated scales for the assessment of patient-reported experiences and outcomes (HLQ, WAI, EORTC-QLQ-C30) in the Results and Discus sion section. 


\section{Statistical analysis}

We present overall response rates, response rates by cancer site and proportions of missing values in the German and the Danish sample for key questions. Moreover, frequency tables of patient reports and ratings of cancer care are shown for selected key questions. Descriptive statistics were performed in SAS 9.4 (Danish analysis) and IBM SPSS Statistics Version 22 (German analysis). No inferential statistics were performed as no hypothesis was tested. All results are exploratory.

\section{Results}

\section{Feasibility, acceptance and applicability}

All contacted hospitals but one were willing to support the study in terms of patient recruitment $(12$ specialised units in seven hospitals out of 13 specialised units in eight hospitals participated). One hospital declined due to the additional administrative burden.

In total, $65.3 \%$ ( $n=160$ out of 245 ) of the German patients responded to the postal questionnaire (Table 1). The response rate was slightly higher than in the Danish survey (response rate $=57.8 \% ; n=1964$ ). In both samples, response rates among breast cancer patients are higher than among colorectal cancer patients. More patients in the German sample reported to have completed treatment and to suffer from comorbid conditions than in the Danish survey.

The missing values analysis showed that the proportion of missing answers to questions ranged from 0.0 to $45.1 \%$ with an average of $7.0 \%$ missing values per question (for detailed information on key questions please see Table 2). Those values are comparable to the results from the Danish survey (data not shown). The highest non-response rate of $45.1 \%$ was observed in a subquestion asking whether complications assessed in the previous question (Have you ever experienced any of the following problems: problems with chemotherapy (e.g. wrong doses or the chemo went outside the vein), not enough treatment against pain, occurrence of inflammation/infection or bedsores/pressure sores, etc.) had any consequences for the patient such as insecurities or prolonged hospitalisation.

We observed that questions asking about the diagnostic process did not fully capture German pathways. Less than a fifth of the German patients stated that their diagnostic process was initiated by a visit to a general practitioner (GP) in contrast to $52 \%$ in Denmark (Table 3). When patients were asked about the timely appropriateness of referrals from GP to specialised care, high missing values were observed in the German study population (Table 2). In general, the assessment of patient experiences in the diagnostic phase heavily focuses on experiences in general practice. Though there are questions filtering for being in contact with the GP in order to avoid
Table 1 Basic characteristics of the study participants in Schleswig-Holstein (SH), Germany and Denmark (DK)

\begin{tabular}{|c|c|c|c|c|c|c|}
\hline & \multicolumn{3}{|c|}{$\begin{array}{l}\text { Schleswig-Holstein (SH), } \\
\text { Germany }\end{array}$} & \multicolumn{3}{|c|}{ Denmark (DK) } \\
\hline & \multicolumn{2}{|c|}{ Total } & \multirow{2}{*}{$\begin{array}{l}\text { Response } \\
\%\end{array}$} & \multicolumn{2}{|l|}{ Total } & \multirow{2}{*}{$\begin{array}{l}\text { Response } \\
\%\end{array}$} \\
\hline & $n$ & $\%$ & & $n$ & $\%$ & \\
\hline Total & 160 & 100.0 & 65.3 & 1964 & 100.0 & 57.8 \\
\hline \multicolumn{7}{|l|}{ Cancer site } \\
\hline Breast & 115 & 71.9 & 68.5 & 1095 & 55.7 & 59.5 \\
\hline Colorectal & 45 & 28.1 & 58.4 & 869 & 44.3 & 55.7 \\
\hline \multicolumn{7}{|l|}{$\operatorname{Sex}^{*}$} \\
\hline Female & 21 & 46.6 & 60.0 & 359 & 41.3 & 52.7 \\
\hline Male & 24 & 53.3 & 57.1 & 510 & 58.7 & 58.1 \\
\hline \multicolumn{7}{|c|}{ Age distribution of breast cancer patients } \\
\hline $30-49$ & 16 & 13.9 & 61.5 & 168 & 15.3 & 51.2 \\
\hline $50-59$ & 34 & 29.6 & 82.9 & 245 & 22.4 & 60.2 \\
\hline $60-69$ & 31 & 27.0 & 67.4 & 332 & 30.3 & 63.6 \\
\hline $70-79$ & 28 & 24.3 & 70.0 & 246 & 22.5 & 65.6 \\
\hline 80-99 & 6 & 5.2 & 40.0 & 104 & 9.5 & 50.0 \\
\hline \multicolumn{7}{|c|}{ Age distribution of colorectal cancer patients } \\
\hline $30-59$ & 11 & 24.4 & 73.3 & 115 & 13.2 & 45.6 \\
\hline $60-99$ & 34 & 75.5 & 54.8 & 754 & 86.8 & 57.7 \\
\hline \multicolumn{7}{|c|}{ Self-reported treatment status } \\
\hline Completed & 109 & 68.1 & - & 1027 & 52.3 & - \\
\hline Ongoing & 42 & 26.3 & - & 805 & 41.0 & - \\
\hline Unknown & 9 & 5.6 & - & 132 & 6.7 & - \\
\hline \multicolumn{7}{|c|}{ Self-reported comorbid conditions } \\
\hline Yes & 85 & 53.1 & - & 813 & 41.2 & - \\
\hline No & 57 & 35.6 & - & 950 & 48.4 & - \\
\hline Unknown & 18 & 11.3 & - & 201 & 10.2 & - \\
\hline
\end{tabular}

"colorectal cancer cases only

that patients answer to questions that are not relevant for them, these were partly ignored by patients or questions about GPs were answered because patients contacted them for other reasons than the suspected cancer disease. Despite these difficulties, respondents showed generally good response behaviour.

\section{Patient experiences and needs}

In total, we analysed 99 questions/multiple item scales with overall 157 items. Tables 3, 4 and 5 and Additional file 2: Table S1 and Additional file 3: Table S2 show the selected questions and answers for the German sample and the Danish sample. Questions were partly abbreviated for better readability of the tables. For original wording please check Table 2.

The majority of cancer patients rated the time from examination at the GP until referral to specialised care as adequate. Roughly $10 \%$ of the survey participants 
Table 2 Proportion of missing values (MV) for key questions from the questionnaire

$\%$ of MV

$\mathrm{SH}$

DK

Diagnostic delay and satisfaction with diagnostic phase

1. How did the process start that led to your diagnosis with cancer?

2. How do you rate the length of time:

a) From your first examination by the general practitioner, until

you were referred to a specialised doctor or hospital?

b) From your referral to examination at a specialised doctor or

c) From when you were told that you had cancer until you received your first treatment?

3. Do you feel you were taken seriously when you attended the general practitioner with your symptoms?

done until you received your diagnosis)?

5. Do you feel your cancer diagnosis was given to you in a proper manner?

6. Is there anything you would have liked to have been different in the period of time from when you were told that you had cancer until your treatment was initiated?

Information \& involvement

7. Before you started treatment, did a doctor or nurse give you the information you needed in relation to:

a) Your disease?

b) Your treatment(s)?

c) Which complications may occur after operation?

d) Which side effect(s) of medicine may occur? (e.g. nausea, sensory disturbance after chemotherapy)

8. Were you sufficiently involved in treatment decisions? Assessed

via agreement or disagreement of answers to the following questions:

treatment were made?*

b) Which statement describes best, how you would prefer

decisions about your treatment are made?*

offered was the right treatment for you?

10. Do you feel that the doctors

a) Treated you like a whole person and was not just interested

in your disease?

b) Took time to understand what was important for you?

Continuity of care

11. Which of the following statements best describes your experience

at the hospital?

One particular doctor was responsible for my overall treatment, etc. (see Additional file 2: Table S1)

12. Did you feel that there was a clear plan for your overall treatment pathway?

13. How do you rate the number of doctors you have been in contact with during your treatment at hospital? you could reach out to if you needed it? 
Table 2 Proportion of missing values (MV) for key questions from the questionnaire (Continued)

\begin{tabular}{|c|c|c|}
\hline & \multicolumn{2}{|c|}{$\%$ of $\mathrm{MV}$} \\
\hline & $\mathrm{SH}$ & DK \\
\hline \multicolumn{3}{|l|}{$\begin{array}{l}\text { 15. Have you received the help you needed from the healthcare } \\
\text { system/municipality in relation to: }\end{array}$} \\
\hline a) Physical rehabilitation? & 8.8 & 8.4 \\
\hline b) Anxiety, sadness or worries (e.g. talks with i.e. a psychologist/priest)? & 10.0 & 10.2 \\
\hline $\begin{array}{l}\text { c) Unexpected weight changes/malnutrition (e.g. dietary } \\
\text { regimen, dietary advice)? }\end{array}$ & 9.4 & 10.9 \\
\hline d) Problems with intimacy or relationships? & 11.9 & 11.0 \\
\hline \multicolumn{3}{|l|}{ Discharge and overall treatment } \\
\hline 16. Did you feel comfortable being discharged from hospital? & 0.9 & 6.7 \\
\hline $\begin{array}{l}\text { 17. Did you get the information you needed about which symptoms } \\
\text { are important for you to respond to? }\end{array}$ & 1.8 & 9.4 \\
\hline 18. Do you know who you can contact at the hospital if you need to? & 0.9 & 6.2 \\
\hline 19. Overall, how do you rate your overall care and treatment at hospital? & 2.5 & 5.0 \\
\hline
\end{tabular}

*Patients could choose between following statements:

A. I make the decisions about which treatment I will receive

B. I make the decisions about which treatment I will receive after considering my doctor's opinion

C. The doctor and I make the decisions together about which treatment I will receive

D. The doctor makes the decision about which treatment I will receive, but he/she seriously considers my opinion

E. The doctor makes the decision about which treatment I will receive without involving me

stated that it took too long. Interestingly, $10 \%$ of the Danish breast and colorectal cancer patients stated that the time in-between examination and referral was too short. Similar patterns were observed regarding the timeliness of diagnosis after examination at specialised care and for initial treatment after diagnosis. More Danish patients felt taken seriously when they presented their symptoms at the GP than German patients, though considerably more German patients stated that this aspect was not relevant to them. The majority of patients were satisfied with the way the cancer diagnosis was delivered. More than $70 \%$ of the participants stated that there was nothing they would have liked to have been different in the period from when they were diagnosed with cancer until treatment was initiated. Of those who indicated potential for improvement, most would have liked to have started treatment sooner (Table 3).

The information need was largely met, though a slight tendency towards the need for more information was observed especially regarding treatment side effects. In both samples, roughly $80 \%$ of the patients indicated that they were sufficiently involved in care decision making. In Denmark, $6.3 \%$ of the study participants stated that they were involved too much, while $13.6 \%$ reported to have been involved to a lesser extent than they had preferred. A similar trend was observed in Germany (3.1 and $17.2 \%)$. The proportion of patients expressing doubt about the appropriateness of offered treatment was also slightly higher among the German cancer patients. The majority of respondents reported that the doctors treated them like a whole person, and were not just interested in the disease and took the time to understand what was important to the patients. Contentment, however, was higher among Danish patients (Table 4).

One fifth of the German respondents and almost a third of the Danish patients reported that they experienced uncertainty with respect to the responsibility of doctors and they stated that they were not always informed about which doctor was responsible for their care or they felt no doctor at all was responsible. Almost $30 \%$ of the Danish breast and colorectal cancer patients stated that (slightly) too many doctors were involved, whereas only $12 \%$ of the German patients reported this (Additional file 2: Table S1).

The need for support was highest in relation to physical rehabilitation followed by dealing with anxiety, sadness or worries and handling unexpected weight changes/malnutrition. The need for physical rehabilitation was largely met, though German cancer patients reported slightly more often than Danish patients that their need was not met adequately. With regard to support in coping with anxiety, sadness or worries, $44 \%$ of the German respondents, who indicated a need, stated that their need was not met. A by far larger proportion of $70 \%$ of the Danish respondents indicated that their need of support in coping with mental distress was not met. The need for support in relation to unexpected weight changes/ malnutrition and problems with intimacy or relationships were largely unmet in both samples (Table 5).

Though the vast majority of patients felt comfortable to be discharged from hospital, more than $20 \%$ of the 
Table 3 Patient-reported experiences during the diagnostic phase and satisfaction with the diagnostic phase

\begin{tabular}{|c|c|c|}
\hline \multirow[t]{2}{*}{ Diagnostic delay and satisfaction with diagnostic phase } & \multirow{2}{*}{$\begin{array}{l}\mathrm{SH} \\
\%\end{array}$} & \multirow{2}{*}{$\begin{array}{l}\text { DK } \\
\%\end{array}$} \\
\hline & & \\
\hline 1. How did the process start that led to your diagnosis with cancer? & $n=140$ & $n=1935$ \\
\hline - I was in contact with my own general practitioner (GP) & 19.3 & 52.3 \\
\hline - I was in contact with a specialist outside of the hospital (e.g. gynaecologist) & 26.4 & 1.1 \\
\hline - I attended cancer screening (e.g. breast-, cervix- or colorectal cancer) & 30.7 & 33.3 \\
\hline - I was treated for another disease at the hospital & 5.0 & 2.9 \\
\hline - I was hospitalized as the result of an emergency & 2.1 & 3.2 \\
\hline - Other & 16.4 & 7.2 \\
\hline \multicolumn{3}{|l|}{ 2. How do you rate the length of time from: } \\
\hline a) examination by the GP until referral to a specialised doctor or hospital? & $n=53$ & $n=973$ \\
\hline - Adequate & 84.9 & 74.8 \\
\hline - Too long & 9.4 & 12.2 \\
\hline - Too short & 0.0 & 9.9 \\
\hline - Not relevant & 5.7 & 3.0 \\
\hline b) referral to examination at a specialised doctor/hospital until receiving the diagnosis? & $n=54$ & $n=975$ \\
\hline - Adequate & 75.9 & 72.2 \\
\hline - Too long & 11.1 & 15.2 \\
\hline - Too short & 1.9 & 9.9 \\
\hline - Not relevant & 11.1 & 2.8 \\
\hline c) cancer diagnosis until you received your first treatment? & $n=158$ & $n=1896$ \\
\hline - Adequate & 86.1 & 79.4 \\
\hline - Too long & 11.4 & 13.8 \\
\hline - Too short & 1.9 & 3.9 \\
\hline - Not relevant & 0.6 & 3.0 \\
\hline 3. Do you feel you were taken seriously when you attended the GP with your symptoms? & $n=60$ & $n=1033$ \\
\hline - Yes, to a great extent & 63.3 & 76.4 \\
\hline - Yes, to some extent & 10.0 & 10.8 \\
\hline - To a lesser extent & 8.3 & 4.5 \\
\hline - No, not at all & 5.0 & 6.2 \\
\hline - Not relevant & 13.3 & 2.2 \\
\hline 4. Overall, how do you rate your diagnostic phase? & $n=149$ & $n=1843$ \\
\hline - Particularly good & 40.3 & 56.5 \\
\hline - Good in the main & 51.7 & 33.2 \\
\hline - Poor in the main & 4.0 & 4.1 \\
\hline - Particularly poor & 2.7 & 2.2 \\
\hline - Not relevant & 1.3 & 4.1 \\
\hline 5. Do you feel your cancer diagnosis was given to you in a proper manner? & $n=158$ & $n=1941$ \\
\hline - Yes, to a great extent & 62.7 & 74.2 \\
\hline - Yes, to some extent & 25.3 & 19.2 \\
\hline - To a lesser extent & 8.2 & 4.0 \\
\hline - No, not at all & 3.8 & 2.7 \\
\hline 6. Is there anything you would have liked to be different? & $n=157$ & $n=1904$ \\
\hline - No, there was nothing else I would have liked & 71.3 & 73.5 \\
\hline - Yes & 28.7 & 26.5 \\
\hline
\end{tabular}


Table 3 Patient-reported experiences during the diagnostic phase and satisfaction with the diagnostic phase (Continued)

\begin{tabular}{|c|c|c|}
\hline \multirow[t]{2}{*}{ Diagnostic delay and satisfaction with diagnostic phase } & $\mathrm{SH}$ & DK \\
\hline & $\%$ & $\%$ \\
\hline \multicolumn{3}{|l|}{ Among those, who stated yes, would have liked } \\
\hline - to have started treatment sooner (e.g. operation, chemotherapy) & 53.3 & 68.5 \\
\hline - to have waited a little longer before I started treatment & 2.2 & 2.4 \\
\hline - more information before I started treatment & 28.9 & 15.1 \\
\hline - a more in depth conversation before I started treatment & 26.7 & 15.5 \\
\hline
\end{tabular}

participants reported, that they did not receive enough information regarding symptoms that need to be reacted to. A similarly high proportion of patients stated, that they do not know, whom they could contact if necessary. Overall however, more than $95 \%$ of the patients rated their care at hospital as particularly good or good in the main (Additional file 3: Table S2).

\section{Discussion}

To our knowledge, this is the first study assessing the feasibility of collecting data with patient-reported experience measures covering the entire patient pathway from diagnosis to discharge from hospital and eliciting information on patients' needs and preferences in oncological care in Germany.

We observed high interest among leading hospital staff to assess patient-reported experiences and outcomes. This resulted in a high participation rate of hospital departments contacted for study purposes. Moreover, the high response rate $(65.3 \%)$ in this survey despite the use of an extensive questionnaire is indicative of relevance for and good acceptance among cancer patients. In contrast to our results, studies report lower response rates to postal surveys on an average of approximately $50-60 \%$ in organisational [36] and medical research [37] with a trend towards declining survey response rates in more recent years [38]. Factors positively influencing response rates are among others high relevance of the surveyed topic to the study population and the implementation of reminder letters $[39,40]$ as done in this study.

Many similarities regarding (non-)response patterns and self-reports from German and Danish patients were observed, but where differences were noted they appear to be plausible. The outlier non-response rate of $45.1 \%$ to a sub-question assessing consequences of complications, which were assessed in the question before, was probably caused by questionnaire layout separating the two questions with a page break. Patients may not have understood what the sub-question was referring to and thus skipped answering it. In future studies such inapt layout will be avoided. Differences were observed regarding treatment status of patients with more German than Danish patients reporting to have completed treatment. As the survey was conducted slightly later in Schleswig-Holstein (6-9 months after diagnosis) than in Denmark (4-7 months after diagnosis), this finding was expected. When asked about the timely appropriateness of referrals from GP to specialised care, high proportions of missing values were observed among the German cancer patients. This might be explained by the fact that referrals from GPs to specialised doctors are wanted but not mandatory in the German health care system and patients can directly consult a specialist whereas GPs have a gatekeeper function in Denmark for referrals to specialised care. Likewise, a rather large proportion of German patients stated that the aspect of having felt taken seriously when they presented their symptoms at the GP was not relevant to them. It is possible that respondents skipped the filter question regarding initial contact to the GP during the diagnostic phase and answered the following GPrelated questions despite not having been in contact with their GP at all or they had been in contact with their GP but for other reasons than their suspected cancer. Overall, only $19.3 \%$ of the German respondents replied that the process leading to their cancer diagnosis was started by a visit to the GP. Thus it seems not to be appropriate to focus on the patient-GP-relationship during the diagnostic phase in Germany. A more thorough pre-test e.g. including cognitive interviews, might have elicited this aspect, which the conventional pre-test failed to identify. However, this observation is limited to breast and colorectal cancer patients and the proportion of patients consulting a GP might be higher among patients of other cancer sites for which no screening programmes are available. In future work, we will shorten but not eliminate the extensive GP-related section of the questionnaire. Another remarkable finding is that unlike German patients, $10 \%$ of the Danish cancer patients stated that the time in-between examination at the GP and referral as well as in-between examination at a specialist and diagnosis were too short. More in-depth analyses exploring qualitative statements from Danish patients showed that many patients did not find the category "adequate" positive enough, and therefore answered "too short". Thus there are reasons to doubt the validity of responses of Danish patients to these items. Another major difference observed was a considerably higher proportion of Danish patients reporting to have met too many doctors and to have experienced no clear 
Table 4 Patient-reported experiences on information need and involvement in care decision making

\begin{tabular}{|c|c|c|}
\hline \multirow[t]{2}{*}{ Information \& involvement in decision making } & $\mathrm{SH}$ & DK \\
\hline & $\%$ & $\%$ \\
\hline \multicolumn{3}{|l|}{ 7. Did you get the information you needed in relation to: } \\
\hline a) Your cancer disease? & $n=154$ & $n=1909$ \\
\hline - Yes, had enough information & 87.0 & 89.3 \\
\hline - Lacked a little information & 9.1 & 7.2 \\
\hline - Lacked a lot of information & 2.6 & 1.2 \\
\hline - Had too much information & 0.6 & 0.6 \\
\hline - Not relevant & 0.6 & 1.7 \\
\hline b) Your treatment option(s)? & $n=142$ & $n=1791$ \\
\hline - Yes, had enough information & 83.1 & 86.2 \\
\hline - Lacked a little information & 12.7 & 8.9 \\
\hline - Lacked a lot of information & 3.5 & 1.8 \\
\hline - Had too much information & 0.0 & 0.4 \\
\hline - Not relevant & 0.7 & 2.7 \\
\hline c) Which complications may occur after operation? & $n=149$ & $n=1772$ \\
\hline - Yes, had enough information & 81.2 & 75.2 \\
\hline - Lacked a little information & 10.7 & 12.0 \\
\hline - Lacked a lot of information & 4.0 & 4.9 \\
\hline - Had too much information & 0.7 & 0.1 \\
\hline - Not relevant & 3.4 & 7.8 \\
\hline d) Which side effects of medicine may occur? & $n=148$ & $n=1784$ \\
\hline - Yes, had enough information & 69.4 & 70.3 \\
\hline - Lacked a little information & 14.2 & 9.4 \\
\hline - Lacked a lot of information & 6.1 & 4.3 \\
\hline - Had too much information & 0.0 & 0.8 \\
\hline - Not relevant & 10.1 & 15.2 \\
\hline 8. Were you sufficiently involved in treatment decisions? & $n=128$ & $n=1670$ \\
\hline - Sufficiently involved & 79.7 & 80.1 \\
\hline - Involved too much & 3.1 & 6.3 \\
\hline - Involved too little & 17.2 & 13.6 \\
\hline 9. Have you ever doubted whether your treatment was the right treatment for you? & $n=152$ & $n=1865$ \\
\hline - No, not at all & 62.5 & 75.0 \\
\hline - To a lesser extent & 8.6 & 9.0 \\
\hline - Yes, to some extent & 15.8 & 8.5 \\
\hline - Yes, to a great extent & 12.5 & 6.7 \\
\hline - Not relevant & 0.7 & 0.9 \\
\hline \multicolumn{3}{|l|}{ 10. Do you feel that the doctors: } \\
\hline a) Treated you like a whole person and were not just interested in your disease? & $n=149$ & $n=1821$ \\
\hline - Yes, all of them & 52.3 & 64.5 \\
\hline - Yes, most of them & 36.2 & 23.6 \\
\hline - Some of them & 8.1 & 8.4 \\
\hline - No, none of them & 1.3 & 1.4 \\
\hline - Don't know & 2.0 & 2.1 \\
\hline b) Took time to understand what was important for you? & $n=148$ & $n=1746$ \\
\hline
\end{tabular}


Table 4 Patient-reported experiences on information need and involvement in care decision making (Continued)

\begin{tabular}{lll}
\hline Information \& involvement in decision making & SH & $\begin{array}{c}\text { DK } \\
\%\end{array}$ \\
\hline - Yes, all of them & 50.0 & 55.8 \\
- Yes, most of them & 34.5 & 26.6 \\
- Some of them & 11.5 & 11.1 \\
- No, none of them & 3.4 & 2.2 \\
- Don't know & 0.7 & 4.3 \\
\hline
\end{tabular}

*The results are based on a calculation of agreement or disagreement between patients' preferences of involvement and patients' experiences of involvement (for original questions see Table 2)

doctor responsibility in comparison to German patients. Higher contentment with regard to the continuity of care among German patients might be explained by the unique structure of German hospitals included in this study. In Schleswig-Holstein, it is common to pool cancer care for the most common cancers at cancer site-specific clinics, so called "cancer centres", which offer more comprehensive care (e.g. multidisciplinary tumour board reviews) than usual hospitals. This way of organising cancer care might result in smoother continuity of care. Likewise, a much lower proportion of German cancer patients reported unmet needs of support in coping with anxiety and depression than Danish patients. This might be a result of both the more specialised care at cancer centres and the potentially higher general awareness of the psycho-oncological burden for cancer patients among German physicians as there are clinical guidelines for psycho-oncological care available in Germany [41] but unfortunately not yet in Denmark.

Overall, the cancer patients evaluated oncological care positively across countries. This finding is not surprising as patient satisfaction and experience surveys often are criticized for producing skewed positive results [42, 43], which reduce opportunities to support changes or improve health care. This survey however, presents more useful results due to the development of a tool with questions specifically targeting cancer patients in contrast to generic tools applied to cancer patients. Rather than asking for general patient satisfaction this survey collects information about actual experiences or specific events e.g. lack of information about treatment options, level of involvement in decisions, insufficient pain management and unmet psychosocial needs and thus enabling targeted quality improvement.

The analysis of this survey, however, focused on descriptive statistics and no analytical statistical tests were performed as the comparisons between the nonrepresentative German sample and the representative Danish sample do not allow generalisable conclusions. Also stratified analyses, e.g. cancer site specific analysis, were not conducted due to the small German sample. Furthermore, the proportion of breast cancer patients was significantly overrepresented in the German population with $72 \%$ of the sample being women with breast cancer compared to $56 \%$ in the Danish sample. Thus, observed differences in evaluated quality of care across countries could partly be due to persistent differences in the quality of care as experienced by breast cancer patients and colorectal cancer patients with breast cancer patients tending to rate care more positively as shown in previous work [44]. Nonetheless, the non-representative German sample might still be indicative of trends and shed light on aspects that might be worth investigating further. As the cancer patients enrolled in this survey were

Table 5 Patient-reported need for support and degree to which the need was met

\begin{tabular}{|c|c|c|c|c|c|c|}
\hline \multirow{2}{*}{\multicolumn{2}{|c|}{$\begin{array}{l}\text { Did you receive the help you needed from health } \\
\text { services in relation to: }\end{array}$}} & \multirow{2}{*}{$\begin{array}{l}\text { Had } \\
\text { a } \\
\text { need }\end{array}$} & \multicolumn{4}{|c|}{ Met need among those who had a need } \\
\hline & & & Yes, to a great extent & Yes, to some extent & To lesser extent & No, not at all \\
\hline \multirow[t]{2}{*}{ Physical rehabilitation } & $\mathrm{SH}(n=146)$ & $57.5 \%$ & $33.3 \%$ & $34.5 \%$ & $17.9 \%$ & $14.3 \%$ \\
\hline & DK $(n=1799)$ & $45.4 \%$ & $51.8 \%$ & $23.2 \%$ & $7.8 \%$ & $17.2 \%$ \\
\hline \multirow[t]{2}{*}{ Anxiety, sadness or worries } & $\mathrm{SH}(n=144)$ & $36.8 \%$ & $30.2 \%$ & $26.4 \%$ & $22.6 \%$ & $20.8 \%$ \\
\hline & DK $(n=1763)$ & $30.4 \%$ & $15.5 \%$ & $15.1 \%$ & $16.5 \%$ & $52.9 \%$ \\
\hline \multirow[t]{2}{*}{ Unexpected weight changes/malnutrition } & $\mathrm{SH}(n=145)$ & $34.5 \%$ & $18.0 \%$ & $18.0 \%$ & $28.0 \%$ & $36.0 \%$ \\
\hline & DK $(n=1750)$ & $34.3 \%$ & $16.3 \%$ & $18.5 \%$ & $18.8 \%$ & $46.3 \%$ \\
\hline \multirow[t]{2}{*}{ Problems with intimacy or relationships } & $\mathrm{SH}(n=141)$ & $19.9 \%$ & $10.7 \%$ & $7.1 \%$ & $7.1 \%$ & $75.0 \%$ \\
\hline & $\mathrm{DK}(n=1747)$ & $24.6 \%$ & $5.8 \%$ & $14.4 \%$ & $20.7 \%$ & $59.1 \%$ \\
\hline
\end{tabular}


treated at cancer centres, the sample might not be entirely representative of all cancer patients with breast and colorectal cancer since other forms of health care provided in specialised outpatient care or university-level medical care are not included. It needs to be investigated whether the higher degree of needs met in psycho-oncological care in Germany compared to Denmark can be attributed to surveying patients treated at hospitals with more comprehensive cancer care or if these cross-border differences persist in a representative large-scale study. Nevertheless, the findings of this pilot study have to be interpreted as rather hypothesis generating.

More importantly, the results deliver information regarding the feasibility of a large-scale patient-reported experience and outcomes study in Schleswig-Holstein, Germany. We showed that the collection of patientreported experience and outcome data for patientcentred quality evaluation in oncological care is feasible within the German health care system using the existing data collection structures for cancer registration purposes in Schleswig-Holstein mirrored by high participation rates of hospital units. Moreover, relatively high response rates and an acceptable average of $7 \%$ missing values per question indicate a satisfactory acceptance of the extensive survey questionnaire among cancer patients. Overall, the response patterns of German and Danish patients were largely consistent. Yet, it was shown that a substantial re-design of questions covering the diagnostic phase is necessary and not all questions can be applied as they were. Characteristics that are unique to the German or Danish health systems need to be taken into account more carefully.

In future work, adaptation efforts have to be strengthened. Shortening the questionnaire might be beneficial in order to yield even higher response rates $[39,40]$ and thus ensuring increased generalisability of the results. The replication of results in a representative study covering all cancer sites is necessary in order to draw generalisable conclusions about the potential strengths and weaknesses of oncological care provided in SchleswigHolstein.

\section{Conclusion}

The pilot study yielded satisfactory results in terms of feasibility, acceptance and applicability. Participation and completeness of answers as well as the response patterns of German and Danish patients are comparable and consistent. We conclude that the translation was successful and feasibility is given. In a future large-scale study comparisons between Denmark and Schleswig-Holstein, Germany should be possible. However, questions heavily related to the Danish health care system have to be adapted to the German setting.

\section{Supplementary information}

Supplementary information accompanies this paper at https://doi.org/10. 1186/s12913-019-4646-4

Additional file 1: Figure S1. Flowchart of the questionnaire adaptation process.

Additional file 2: Table S1. Patient reports and ratings of experiences during the treatment phase at hospital.

Additional file 3: Table S2. Patient-reported experiences at discharge from hospital and satisfaction with overall care at hospital.

\section{Abbreviations}

EORTC QLQ-C30: Quality of Life Questionnaire by the European Organisation for Research and Treatment of Cancer containing 30 core questions; GP: General Practitioner; HLQ: Health Literacy Questionnaire; PREM: Patientreported experience measure; PROM: Patient-reported outcome measure; WAl: Work Ability Index

\section{Acknowledgements}

We would like to thank Dr. Valentin Babaev and all participating clinical partners, namely Prof. Dr. Oliver Behrens and Dr. Christos Papachrysanthou from Imland Klinik Rendsburg, PD Dr. Ivo Heer, Dr. Ingrid Buck and PD Dr. Nicolas Schwarz from Friedrich-EbertKrankenhaus Neumünster, Dr. Uwe Heilenkötter and Prof. Dr. Michael Neipp from Klinikum Itzehoe, Dr. Thomas Kunz, Dr. Sandra Rauen, Dr. Marc Olaf Liedke and Dr. Thomas Eibisch from Westküstenklinikum Heide, Dr. Stefan Geist, Dr. Peter Paluchowski and PD Dr. Hamid Mofid from RegioKlinikum Pinneberg, Dr. Christian Wilke from RegioKlinikum Elmshorn and Dr. Horst Ostertag from Evangelisch-lutherische

Diakonissenanstalt Flensburg for supporting the recruitment of patients via the Oncological Care Registry (Onkologisches Versorgungsregister (OVR)) in Schleswig-Holstein. Additionally, we would like to thank Elise Burmeister, who facilitated the translation process of the questionnaire as bilingual communication consultant.

\section{Authors' contributions}

$\mathrm{CR}$ contributed to the design of the study, to the translation process and acquisition of German data, conducted the analyses for German data, interpreted the data from both countries and drafted the manuscript. GSP contributed to the acquisition and analysis of the Danish data, interpreted the data from both countries and critically revised the manuscript. RP contributed to the translation process, to the interpretation of data and critically revised the manuscript. HS contributed to the interpretation of data and critically revised the manuscript. AK conceived the idea for the study, together with CR designed the study, contributed to the translation process and to the interpretation of data, supervised analyses and critically revised the manuscript. All authors read and approved the final manuscript.

\section{Funding}

This work was part of the Interreg-project InnoCan, which was funded by the European Regional Development Fund through the Interreg Deutschland-Danmark programme (reference number: 11-1.0-15). The funding body has no role in the design of the study, in collection, analysis and interpretation of the data and in writing of the manuscript.

Availability of data and materials

The datasets used and/or analysed during the current study are available from the corresponding author on reasonable request.

\section{Ethics approval and consent to participate}

The German pilot study has been approved by the ethics committee of the University of Lübeck (reference number: AZ 17-163). Written consent was obtained from all individual German participants included in the study. The Danish study was approved by the Danish Data Protection Agency (reference number: Journal nr. 2014-41-3006). Under Danish law, questionnaire studies are not subject to review by the Ethics Committee System (LBK nr 1083, §14. Stk 2, 15/09/2017). 


\section{Consent for publication}

Not applicable.

\section{Competing interests}

The authors declare that they have no competing interests.

\section{Author details}

'Institute for Cancer Epidemiology, University of Lübeck, Ratzeburger Allee 160, 23562 Lübeck, Germany. ${ }^{2}$ Danish Cancer Society, Strandboulevarden 49, 2100 København, Denmark.

Received: 29 July 2019 Accepted: 16 October 2019

Published online: 01 November 2019

\section{References}

1. Blumenthal D. Quality of care — what is it? N Engl J Med. 1996:335(12):891-4.

2. Black N, Jenkinson C. Measuring patients' experiences and outcomes. BMJ. 2009;339:b2495.

3. Kingsley C, Patel S. Patient-reported outcome measures and patientreported experience measures. BJA Education. 2017;17(4):137-44.

4. John MT, LeResche L, Koepsell TD, Hujoel P, Miglioretti DL, Micheelis W. Oral health-related quality of life in Germany. Eur J Oral Sci. 2003; 111(6):483-91.

5. Ziegler S, Huscher D, Karberg K, Krause A, Wassenberg S, Zink A. Trends in treatment and outcomes of rheumatoid arthritis in Germany 1997-2007: results from the National Database of the German collaborative arthritis Centres. Ann Rheum Dis. 2010;69(10):1803-8.

6. Quinque EM, Villringer A, Kratzsch J, Karger S. Patient-reported outcomes in adequately treated hypothyroidism - insights from the German versions of ThyDQoL, ThySRQ and ThyTSQ. Health Qual Life Outcomes. 2013;11:68

7. Schäffler N, Schönberg P, Stephan J, Stellmann J-P, Gold SM, Heesen C. Comparison of patient-reported outcome measures in multiple sclerosis. Acta Neurol Scand. 2013;128(2):114-21.

8. Bradley $C$, Eschwège $E$, de Pablos-Velasco $P$, Parhofer $K G$, Simon $D$, Vandenberghe $H$, et al. Predictors of quality of life and other patientreported outcomes in the PANORAMA multinational study of people with type 2 diabetes. Diabetes Care. 2018;41(2):267-76.

9. Arndt V, Merx H, Stegmaier C, Ziegler H, Brenner $H$. Quality of life in patients with colorectal cancer 1 year after diagnosis compared with the general population: a population-based study. J Clin Oncol. 2004; 22(23):4829-36

10. Waldmann A, Pritzkuleit $R$, Raspe $H$, Katalinic A. The OVIS study: health related quality of life measured by the EORTC QLQ-C30 and -BR23 in German female patients with breast cancer from Schleswig-Holstein. Qual Life Res. 2007;16(5):767-76.

11. Puetzler J, Feldmann RE, Brascher A-K, Gerhardt A, Benrath J. Improvements in health-related quality of life by comprehensive cancer pain therapy: a pilot study with breast cancer outpatients under palliative chemotherapy. Oncol Res Treat. 2014;37(9):456-62.

12. Rana M, Gellrich N-C, Rana M. Comparison of health-related quality of life of patients with different precancer and oral cancer stages. Clin Oral Investig. 2015;19(2):481-8.

13. Trautmann F, Hentschel L, Hornemann B, Rentsch A, Baumann M, Ehninger $\mathrm{G}$, et al. Electronic real-time assessment of patient-reported outcomes in routine care-first findings and experiences from the implementation in a comprehensive cancer center. Support Care Cancer. 2016;24(7):3047-56.

14. Berger B, Lenz M, Mühlhauser I. Patient zufrieden, Arzt gut?: Inwiefern ist Patientenzufriedenheit ein Indikator für die Qualität der hausärztlichen Versorgung? Zeitschrift für Evidenz, Fortbildung und Qualität im Gesundheitswesen. 2008;102(5):299-306

15. Brinkmann A, Steffen P, Pfaff H. Patientenbefragungen als Bestandteil des Qualitätsmanagements in Arztpraxen: Entwicklung und Erprobung eines Instrumentes. Gesundheitswesen. 2007:69(11):585-92.

16. Schoenfelder T, Klewer J, Kugler J. Determinants of patient satisfaction: a study among 39 hospitals in an in-patient setting in Germany. Int J Qual Health Care. 2011;23(5):503-9.
17. Kraska RA, Weigand M, Geraedts M. Associations between hospital characteristics and patient satisfaction in Germany. Health Expect. 2017; 20(4):593-600.

18. Jenkinson C, Coulter A, Bruster S. The picker patient experience questionnaire: development and validation using data from in-patient surveys in five countries. Int J Qual Health Care. 2002;14(5):353-8

19. Pfaff $H$, Steffen $P$, Brinkmann A, Lütticke J, Nitzsche A. Der Kölner Patientenfragebogen: Kennzahlenhandbuch; 2004.

20. Lecher S, Klapper B, Koch U. Hamburger Fragebogen zum Krankenhausaufenthalt (HFK): Ein Instrument zur Defizitanalyse aus Patientensicht. Z Med Psychol. 2002;11(3):129-38.

21. Pfaff H, Nitzsche A, Scheibler F, Steffen P. Der Kölner Patientenfragebogen für Brustkrebs (KPF-BK): Kennzahlenhandbuch; 2009.

22. Kleeberg UR, Feyer $P$, Günther W, Behrens M. Patient satisfaction in outpatient cancer care: a prospective survey using the PASQOC questionnaire. Support Care Cancer. 2008;16(8):947-54.

23. Jensen $H$, Tørring ML, Olesen F, Overgaard J, Vedsted P. Cancer suspicion in general practice, urgent referral and time to diagnosis: a population-based GP survey and registry study. BMC Cancer. 2014;14:636.

24. Veloso AG, Sperling C, Holm LV, Nicolaisen A, Rottmann N, Thayssen S, et al. Unmet needs in cancer rehabilitation during the early cancer trajectory--a nationwide patient survey. Acta Oncol. 2013;52(2):372-81.

25. Hellbom M, Bergelt C, Bergenmar M, Gijsen B, Loge JH, Rautalahti M, et al. Cancer rehabilitation: a Nordic and European perspective. Acta Oncol. 2011; 50(2):179-86.

26. Petersen GS, Knudsen JL, Vinter MM. Cancer patients' preferences of care within hospitals: a systematic literature review. Int J Qual Health Care. 2015; 27(5):384-95.

27. Ahmed F, Burt J, Roland M. Measuring patient experience: concepts and methods. Patient. 2014;7(3):235-41.

28. Anhang Price R, Elliott MN, Zaslavsky AM, Hays RD, Lehrman WG, Rybowski $L$, et al. Examining the role of patient experience surveys in measuring health care quality. Med Care Res Rev. 2014;71(5):522-54.

29. Sandager $M$, Sperling $C$, Jensen $H$, Vinter MM, Knudsen JL. Danish cancer patients' perspective on health care: results from a national survey. Cogn Tech Work. 2015;17(1):35-44.

30. Dyg Sperling C, Stentebjerg Petersen G, Hølge-Hazelton B, Graugaard C, Falck Winther J, Gudmundsdottir T, et al. Being young and getting cancer: development of a questionnaire reflecting the needs and experiences of adolescents and young adults with cancer. J Adolesc Young Adult Oncol. 2017:6(1):171-7.

31. Kræftens Bekæmpelse. Kræftpatienters behov og oplevelser med sundhedsvæsenet under udredning og behandling: Kræftens Bekæmpelse Barometerundersøgelse, 2017. Copenhagen: Kræftens Bekæmpelse; 2018.

32. Nolte $\mathrm{S}$, Osborne RH, Dwinger S, Elsworth GR, Conrad ML, Rose M, et al. German translation, cultural adaptation, and validation of the Health Literacy Questionnaire (HLQ). PLoS One. 2017:12(2):e0172340.

33. Hasselhorn HM, Freude G. Der Work Ability Index: Ein Leitfaden. Bremerhaven: Wirtschaftsverl. NW Verl. für neue Wiss; 2007. (Schriftenreihe der Bundesanstalt für Arbeitsschutz und Arbeitsmedizin Sonderschrift; vol 87)

34. EORTC Quality of Life Group. Quality of life of cancer patients - translations. 2019. [cited 2019 May 24]. Available from: https://qol.eortc.org/ questionnaire/eortc-qlq-c30/.

35. Larsen MB, Jensen $H$, Hansen RP, Olesen F, Vedsted P. Identification of patients with incident cancers using administrative registry data. Dan Med J. 2014;61(2):A4777.

36. Baruch $Y$, Holtom BC. Survey response rate levels and trends in organizational research. Hum Relat. 2008;61(8):1139-60.

37. David Asch M, Jedrziewski K, Christakis N. Response rates to mail surveys published in medical journals. J Clin Epidemiol. 1997:50(10): 1129-36.

38. Galea S, Tracy M. Participation rates in epidemiologic studies. Ann Epidemiol. 2007;17(9):643-53.

39. Nakash RA, Hutton JL, Jørstad-Stein EC, Gates S, Lamb SE. Maximising response to postal questionnaires--a systematic review of randomised trials in health research. BMC Med Res Methodol. 2006;6:5.

40. Edwards P, Roberts I, Clarke M, DiGuiseppi C, Pratap S, Wentz R, et al. Increasing response rates to postal questionnaires: systematic review. BMJ. 2002;324:1183. 
41. Leitlinienprogramm Onkologie (Deutsche Krebsgesellschaft, Deutsche Krebshilfe, AWMF). Psychoonkologische Diagnostik, Beratung und Behandlung von erwachsenen Krebspatienten, Langversion 1.1. Berlin: Leitlinienprogramm Onkologie der Arbeitsgemeinschaft der

Wissenschaftlichen Medizinischen Fachgesellschaften e. V. (AWMF),

Deutschen Krebsgesellschaft e. V. (DKG) und Deutschen Krebshilfe e. V. (DKH); 2014.

42. Bjertnaes O, Iversen HH, Garratt AM. The universal patient centeredness questionnaire: scaling approaches to reduce positive skew. Patient Prefer Adherence. 2016;10:2255-60.

43. Williams B, Coyle J, Healy D. The meaning of patient satisfaction: an explanation of high reported levels. Soc Sci Med. 1998;47(9):1351-59.

44. Heerdegen ACS, Petersen GS, Jervelund SS. Determinants of patient satisfaction with cancer care delivered by the Danish healthcare system. Cancer. 2017;123(15):2918-26.

\section{Publisher's Note}

Springer Nature remains neutral with regard to jurisdictional claims in published maps and institutional affiliations.

Ready to submit your research? Choose BMC and benefit from:

- fast, convenient online submission

- thorough peer review by experienced researchers in your field

- rapid publication on acceptance

- support for research data, including large and complex data types

- gold Open Access which fosters wider collaboration and increased citations

- maximum visibility for your research: over $100 \mathrm{M}$ website views per year

At BMC, research is always in progress.

Learn more biomedcentral.com/submissions 